Int. J. Electrochem. Sci., 13 (2018) 4876 - 4890

\title{
Influence of High Temperature, Stress and Chloride Ions on Protection Mechanism of Passive Film on 304 Stainless Steel
}

\author{
Shanlin $\mathrm{He}^{1, *}$, Daming Jiang ${ }^{1}$ \\ School of Materials Science and Engineering, Harbin Institute of Technology, Harbin 150001, China \\ *E-mail: 11B909025@hit.edu.cn
}

doi: $10.20964 / 2018.05 .32$

Received: 24 January 2018 / Accepted: 6 March 2018 / Published: 10 April 2018

\begin{abstract}
X-ray photoelectron spectroscopy (XPS), atomic force microscopy (AFM) and electrochemical impedance spectroscopy (EIS) were used to analyze the changes in content of chemical compounds, surface morphology and electrochemical properties of the passive film on 304 stainless steel under the combined effect of high temperature, stress and $\mathrm{Cl}^{-}$. The protection mechanism of the passive film was investigated. The results showed that the content of chemical compounds experienced changes at different immersion conditions. With increasing immersion time, the ratio between each oxide would level off at different stable values for each immersion condition. The passive film at the surface of the grain boundary was damaged due to the dissolution of chemical compounds. When the surface morphology was damaged, the concentration of the $\mathrm{Cr}_{2} \mathrm{O}_{3}$ can not accurately reflect the corrosion resistance of the passive film. The decrease in the corrosion resistance of the passive film was mainly attributed to the corrosion groove, which was formed from the dissolution of the passive film on the surface of the grain boundary.
\end{abstract}

Keywords: combined effect; surface morphology; corrosion groove; dissolution; corrosion resistance

\section{$\underline{\text { FULL TEXT }}$}

(C) 2018 The Authors. Published by ESG (www.electrochemsci.org). This article is an open access article distributed under the terms and conditions of the Creative Commons Attribution license (http://creativecommons.org/licenses/by/4.0/). 